\title{
Range Extension for an Endangered Marmoset
}

\author{
Russell A. Mittermeier, Adelmar F. Coimbra-Filho and \\ Isabel D. Constable
}

During a field expedition in eastern Brazil the authors found a new population of the endangered buffy-headed marmoset Callithrix flaviceps in the state of Tinas Gerais where it was not previously known. This was in a privately protected forest that also has an important population of the endangered woolly spider monkey Brachyteles arachnoides and other monkeys.

The South American marmoset genus Callithrix is almost entirely confined to Brazil, with only one subspecies, $C$. argentata melanura, extending into adjacent parts of eastern Bolivia.*

Of the eastern Brazilian species the buffy-headed marmoset flaviceps has by far the smallest range of any South American monkey, and also one of the most restricted. Maps provided by Hershkovitz $(490,491)$ show it only in the state of Espírito Santo between the Rio Doce and the Rio de Janeiro-Espírito Santo border, from $19^{\circ} 49^{\prime} \mathrm{S}, 40^{\circ} 16^{\prime} \mathrm{W}$ south and west to $21^{\circ} 02^{\prime} \mathrm{S}, 41^{\circ} 40^{\prime} \mathrm{W} .^{2}$ The IUCN Red Data Book lists it as endangered, primarily because of widespread habitat destruction within its small range, and it appears on both the Brazilian and US Endangered Species Lists as well as Appendix I of CITES.

However, on a recent field trip for the WWF-US Primate Program for Eastern Brazil, we were able to confirm that this monkey also occurs in the neighbouring state of Minas Gerais, on the Fazenda Montes Claros, a private farm owned by Sr Feliciano Miguel Abdala. This is on the Caratinga-Ipanema road, $58 \mathrm{~km}$ from Caratinga and $22 \mathrm{~km}$ from Ipanema (municipality of Caratinga). The main crop is coffee, but the fazenda also has about 1120 hectares of continuous forest which has been protected by Sr Adbala since 1944 and by the previous owner for an unknown period of time. This forest is an important refuge for the woolly spider monkey Brachyteles arachnoides, the largest of the New World monkeys and another of the highly endangered eastern Brazilian primates; our original purpose had been to investigate its status here. Montes Claros, which may be the last place in the state where it can still be found, is one of the few remaining forest patches in an area once known as the state's 'Zona da Mata' (forest zone). It also holds significant populations of the brown howler Alouatta fusca and the tufted capuchin monkeys Cebus apella, as noted by Nishimura. ${ }^{3}$ But we were surprised to discover the buffy-headed marmoset.

We saw the marmosets in three different places. Two groups, each observed only once, numbered three and at least four individuals. Another group, which fed on the gums of a single large angico tree Anandenanthera peregrina (Piptadenia peregrina: Leguminosae Mimosoideae) for five consecutive days,

\footnotetext{
* Hershkovitz recognizes three species in the genus: Callithrix humeralifer (with three subspecies) from lower Amazonia; $C$. argentata (with three subspecies) from lower Amazonia, central Brazil and Bolivia; and $C$. jacchus (with five subspecies) from eastern Brazil. Coimbra-Filho and Mittermeier, on the other hand, consider the five eastern Brazilian taxa to be distinct species and discuss two subspecies in this group as well.
} 


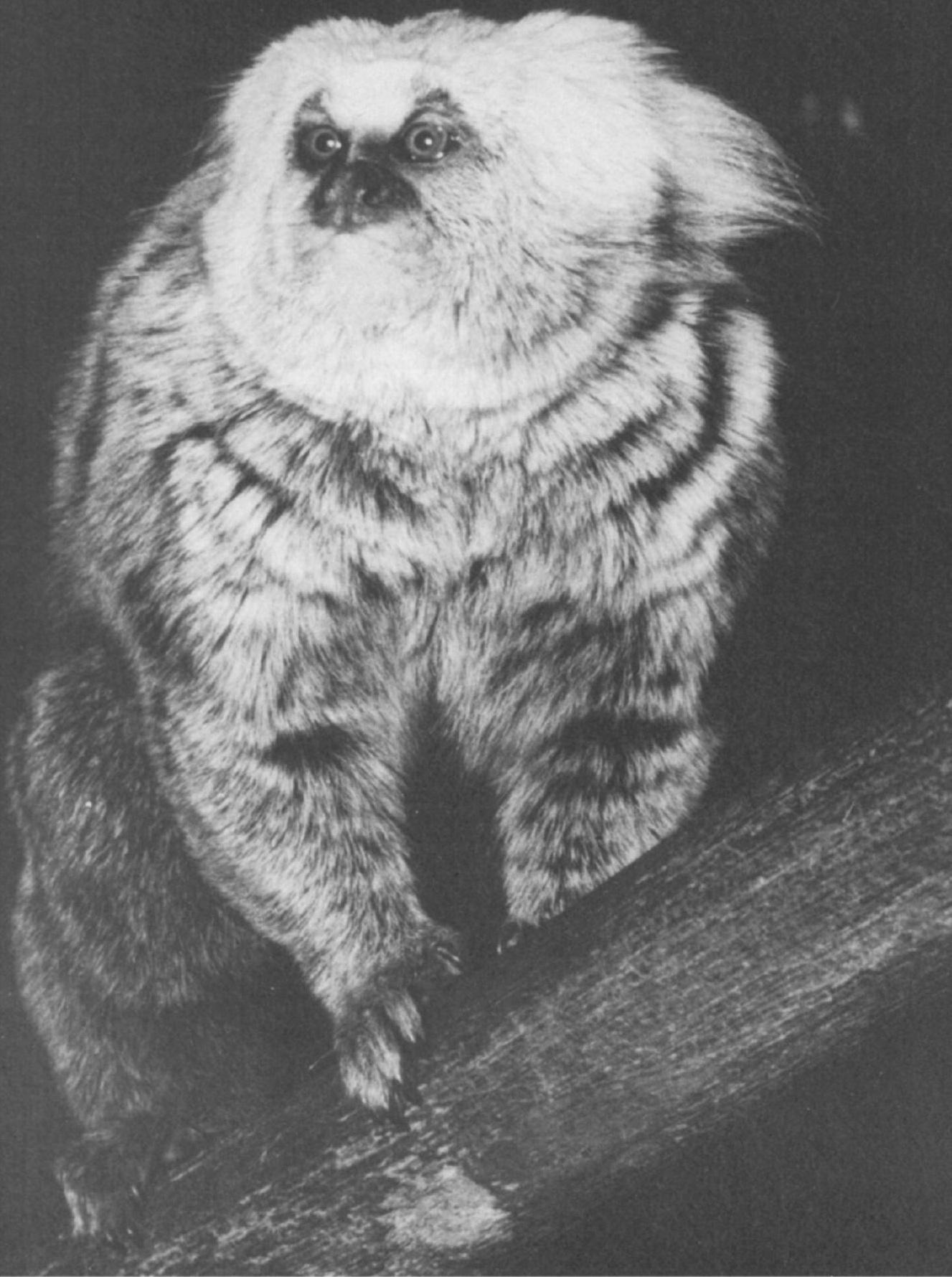

Buff-headed marmoset

Adelmar F. Coimbra-Filho

381 


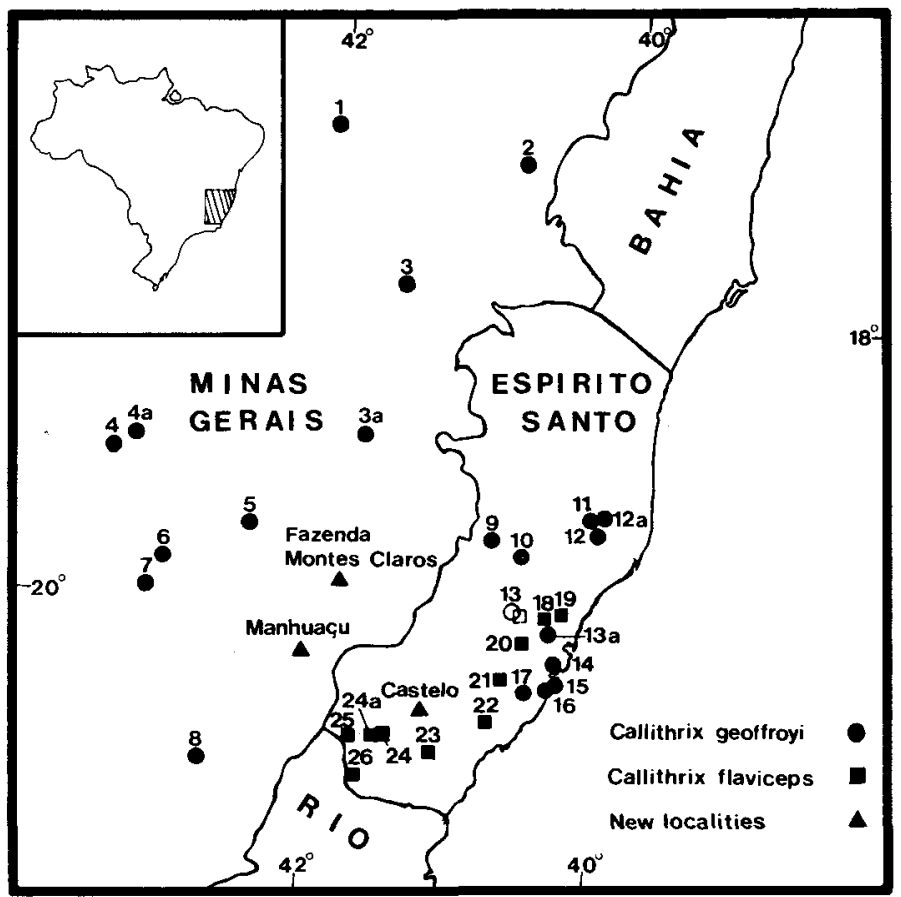

consisted of eight animals. Our fourth observation was of a single animal foraging close to a large group of tufted capuchins.

Although our observations are the first sightings of $C$. flaviceps in the wild in Minas Gerais, there was already evidence that the species probably occurred there. In November 1971 C.A. Campos Seabra had obtained a captive specimen at $\mathrm{Km} \mathbf{4 0 5}$ on the Rio-Bahia road, municipality of Manhuaçu, which was said to have come from forest nearby. The animal was kept alive for several months in the Department of Environmental Conservation (DECAM-FEEMA) in Rio, but later escaped. The record is cited by Coimbra-Filho, ${ }^{1}$ but is not mentioned by Hershkovitz, perhaps because it was not based on a preserved museum specimen.

The Montes Claros record extends this marmoset's range approximately $125 \mathrm{~km}$ to the west and $115 \mathrm{~km}$ to the north of the two closest Espírito Santo localities (Santa Teresa and Guaçuí) mentioned in Hershkovitz. ${ }^{2}$ It also places it well within the range of the white-faced marmoset $C$. geoffroyi, the other Callithrix species known to occur in this part of Minas Gerais. We did not find this species, but local people indicated that a 'sagui caratinga' or 'sagui-decara-branca' (white-faced marmoset) was present. The possibility that these two species exist sympatrically in the area will be investigated at a later date. We counted a group of at least 38 Brachyteles in addition to the $C$. flaviceps, and our studies indicate that the populations of Cebus apella and Alouatta fusca are even larger.

Montes Claros is thus a very important conservation area. Our studies indicate that there are at least 20 and perhaps as many as $50 \mathrm{C}$. flaviceps in the forest there, and it is only the second protected area in which this monkey has been confirmed - the first is the Nova Lombardia National Park in Espirito Santo where we have also seen it. It may also occur in Caparaó National Park, but this remains to be determined. Montes Claros is also one of the few (perhaps the only?) areas left that protects two of the five most endangered 


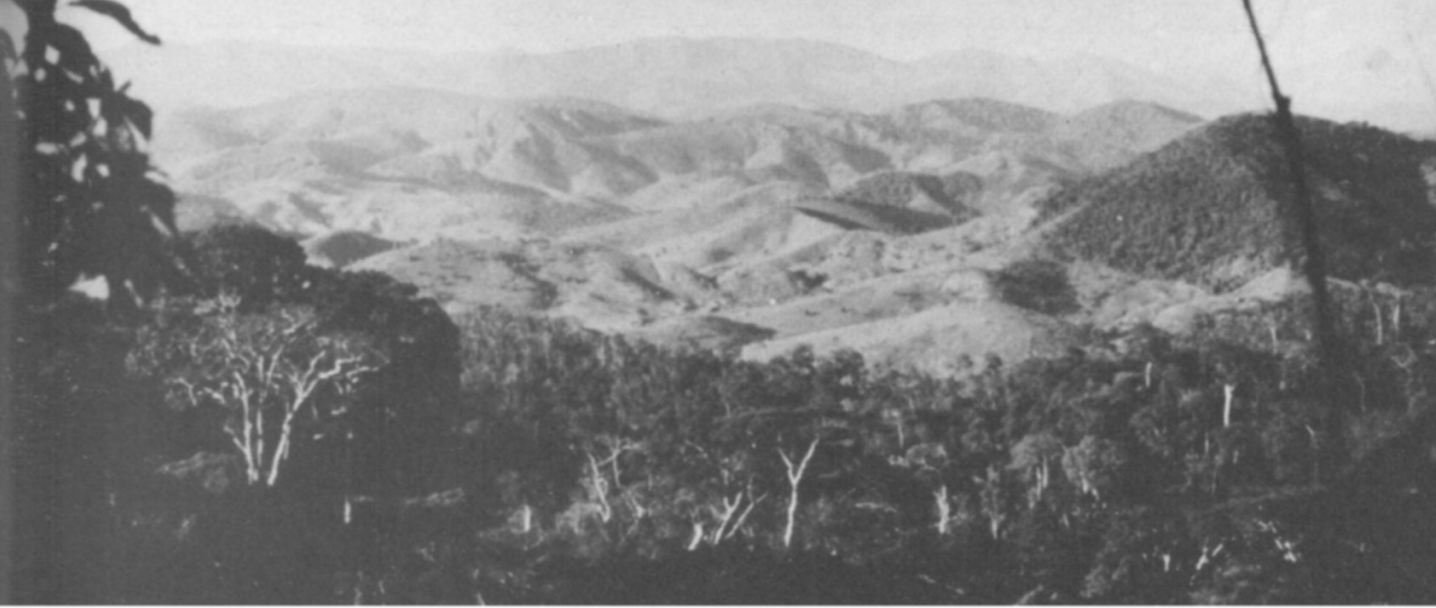

Part of the Monte Claros forest. The barren hills behind were once covered with forest.

RussellA. Mittermeier

eastern Brazilian monkeys - the others are the three lion tamarins Leontopithecus. Several endangered birds also live in Montes Claros, among them the solitary tinamou Tinamus solitarius and the blue-throated conure Pyrrhura cruentata.

Clearly this unique area is of great importance in conserving the rapidly disappearing eastern Brazilian fauna. Sr Abdala is an ardent conservationist; he has protected Montes Claros for 35 years and hopes that it will be preserved for posterity. To ensure this, the area should be bought by the Brazilian government and turned into a National Biological Reserve or an Ecological Station as soon as possible.

\section{Acknowledgments}

We would like to express our thanks to Sr Feliciano Miguel Abdala, owner of Fazenda Montes Claros, for his hospitality and assistance during our visit to Montes Claros, as well as for his efforts in conserving a part of Brazil's superb primate fauna. Thanks also to Celio Valle and Maria Ignes Ferolla for providing information on Montes Claros. This investigation was conducted as part of the WWF-US Primate Conservation Programme for Eastern Brazil, a ioint programme with the Rio de Janeiro Primate Center (CPRJ-FEEMA) and the Brazilian Forestry Development Institute (IBDF).

\section{References}

1. COIMBRA-FILHO, A.F., and R.A. MITTERMEIER 1973. New data on the taxonomy of the Brazilian marmosets of the genus Callithrix Erxleben, 1777.Folia primatol. 20: 241-264.

1a. COIMBRA-FILHO, A.F. 1972. Mamiferos ameaçados do Brasil. In Especies da Fauna Brasileria ameaçadas de Extinção. Academia Brasileira de Ciencias, Rio de Janeiro.

2. HERSHKOVITZ, P 1977. Living New World Monkeys (Platyrrhini). Univ. of Chicago Press.

3. NISHIMURA, A. 1979. In search of woolly spider monkey. Kyoto Univ. Overseas Res. Rep. New World Monkeys (1979): 21-37.

This paper is Misc. Contribution ${ }^{*} l$ from the IUCN/SSC Primate Specialist Group.

Russell A. Mittermeier, World Wildlife Fund - US, 1601 Connecticut Ave. NW, Washington, DC 20009; and Dept. of Anatomical Sciences, Health Sciences Centre, State University of New York, Stony Brook, NY 11794, USA.

Adelmar F. Coimbra-Filho, Centro de Primatologia do Rio de Janeiro DECAM-FEEMA, Rio de Janeiro, Brazil.

Isabel D. Constable, Brown University, Providence, Rhode Island 02912, USA. 